\title{
TIANXIA, TEORÍA DE LAS RELACIONES INTERNACIONALES Y ASCENSO GLOBAL DE CHINA
}

\author{
Manuel MontobBio*
}

1. Mueven las ideas el ejercicio del poder en el Sistema Internacional; y se ejerce el poder en este para producir las ideas y normas que determinan su funcionamiento. Interrelación entre poder para las ideas e ideas para el poder. Como muestra el hecho de que los cambios en la estructura y equilibrio de poder del Sistema han conllevado el de las ideas en que se basa este y su funcionamiento. De ahí que el poder de un actor en el seno del Sistema Internacional sea también el de formulación y promoción de ideas como paradigma dominante. Ideas en el Sistema Internacional, y sobre el Sistema Internacional y la Política Exterior. Pues se basan en definitiva las reglas que orientan y regulan el funcionamiento del Sistema Internacional y este mismo en conceptos compartidos.

2. Vivimos una era de cambio y un cambio de era, determinado por la globalización de la sociedad de la información y sus efectos. Determinado, también, por el desplazamiento del centro de gravedad global hacia Asia Pacífico y la emergencia simultánea de China e India. Determinado por la conformación de China como potencia global y su centralidad en el Sistema Internacional. Lo que plantea la cuestión de si dicha emergencia y transformación va a conllevar simplemente un cambio de la estructura, distribución y equilibrios de poder en el Sistema Internacional existente, o una reconfiguración del mismo y de las ideas y paradigmas en que se sustenta.

3. Sostiene la «maldición de Tucídides» que el cambio de potencia hegemónica en el Sistema Internacional es resultado de una confrontación de esta con la anterior. Parece la intuición decirnos que puede cumplirse la maldición de Tucídides si seguimos en el mundo la lógica de Tucídides, la lógica tesis-antítesis-síntesis que caracteriza la visión occidental de la Historia; mas

* Diplomático y Doctor en Ciencias Políticas, es autor de Ideas chinas. El ascenso global de China y la Teoría de las Relaciones Internacionales (Barcelona, Icaria-Real Instituto Elcano, 2017) (manuel. montobbio@yahoo.es y en cuenta de Twitter@ManuelMontobbio). 
no necesariamente si, al tiempo que asistimos a esa emergencia y a la transformación de la distribución del poder que conlleva, construimos un mundo distinto de una manera distinta. Es en ese contexto y con esa potencial trascendencia que está teniendo lugar en China un proceso de búsqueda y propuesta para la reformulación de la Teoría de las Relaciones Internacionales. Un debate con una doble dimensión internacional y nacional, reflejo y expresión del ascendente posicionamiento de China en la geopolítica del pensamiento, a partir de su reelaboración en el mundo académico chino de la Teoría de las Relaciones Internacionales desde y a partir de la propia realidad, desde la propia tradición de pensamiento y cultura políticos, sean obras de Filosofía política u otras global y horizontalmente referenciales de la cultura china. Y se da para ello un proceso de búsqueda inspiradora en las de la propia tradición, que encuentra dos grandes fuentes: por un lado, la obra de las siete grandes figuras de la Filosofía política china anterior a la unificación Qin en el 221 a. .C -Lao-Tse, Confucio, Mencio, Mozi, Zhuangzi, Xunzi y Hanfeizi-, única etapa de la Historia de China en que esta vivió, salvando las distancias, en un sistema de varias potencias comparable al sistema internacional contemporáneo, pues posteriormente fue considerado el Emperador, el Hijo del Cielo, el Señor de "Todo bajo el cielo», y el Imperio del Centro, el centro de un sistema de dominios tributarios extendido hasta los límites de la Tierra conocida; por otro, Las estratagemas de los reinos combatientes, texto fundacional de la historiografía china - comparable en ello al de Tucídides-, del que tantas lecciones se han extraído y se extraen en la formulación de estrategias políticas. Búsqueda en las fuentes con el propósito de extraer conceptos útiles para la formulación o reformulación de la Teoría de las Relaciones Internacionales, desarrollada, como veremos a continuación, fundamentalmente en tres direcciones - los que Qin Yaqin denomina enfoques anverso, reverso e interactivo, en función de su relación con la Teoría de las Relaciones Internacionales elaborada en Occidente-.

4. Mientras la primera se refiere a la interpretación de la realidad a través de un sistema conceptual chino establecido y la segunda emplea un sistema conceptual extranjero - en este caso, la Teoría occidental de las Relaciones Internacionales - para interpretarla, la interactiva construye un diálogo intercultural, reflexivo y crítico, que aplica simultáneamente marcos conceptuales autóctonos y extranjeros. Corrientes que cuentan cada una con figuras referenciales: Zhao Tingyiang y su Teoría del Sistema de la Tianxia en el enfoque anverso; Yan Xuetong y su obra Ancient Chinese Thought, Modern Chinese Power en el reverso; y Qin Yaqin con su Teoría de la Relacionalidad en el interactivo.

5. Aproximaciones alternativas, con un elemento común: el de constituir expresión e instrumento del paso de los «valores asiáticos» a las ideas asiáticas. Pues, así como la primera oleada proclamatoria de los "valores asiáticos» en los años noventa insistía precisamente en estos, en los valores, como clave o perspectiva alternativa desde la que interpretar y realizar ideas universales y compartidas; hemos asistido al surgimiento de un modelo de desarrollo y 
gobernanza alternativo, cuyo éxito se basa en ideas distintas, de modo que la primera década de este siglo se contemplará en perspectiva como la del paso de los «valores asiáticos» a las ideas asiáticas, del que es expresión el replanteamiento de la Teoría de las Relaciones Internacionales objeto de análisis.

6. Construye Zhao Tingyang su teoría a partir del concepto de Tianxia - lo que está bajo el cielo- y se remonta al sistema creado bajo este durante la dinastía Zhou (1046-256 a. C.) para sostener que era el sistema mundial ideal, que se basaba en tres ideas subyacentes: «En primer lugar, las soluciones a los problemas de la política mundial dependen de un sistema mundial universalmente aceptado y no de la fuerza coercitiva; en segundo lugar, dicho sistema está justificado en términos políticos si sus acuerdos institucionales benefician a todos los pueblos de todas las naciones; y, en tercer lugar, dicho sistema funciona si genera armonía entre todas las naciones y todas las civilizaciones». Un sistema global necesariamente diferente al basado en la polis, pues se refiere «el Tianxia a la política del mundo, siendo así esencialmente diferente de la práctica griega de la polis que se reduce a la política de los Estados», basado en la extensión al conjunto del mundo de la idea de la sociedad familiar, caracterizada por la integridad del vínculo familiar, de modo que "la cuestión del ego-alter no se plantea en absoluto». Lo que le lleva a considerar el mundo actual como «un "no mundo" que, en el plano filosófico e institucional, no es un mundo en absoluto», sino más bien como un escenario geográfico en el que realizar los intereses de los Estados que la encarnación de un sujeto colectivo; y plantea el reto de convertir el «no mundo» en un verdadero mundo a partir de la toma de conciencia del vínculo familiar universal.

7. Al intentar desarrollar un enfoque que combine las Teorías Internacionales occidentales con el pensamiento cultural chino, parte Qin Yaqin de la tesis de que las Teorías Sociales occidentales se basan en la racionalidad, mientras el pensamiento tradicional chino se basa en la idea de relacionalidad, que Confucio consideró la conceptualización fundamental de la gobernanza. Y a partir de ese concepto, desarrolla una Teoría de la Relacionalidad con tres componentes fundamentales: el proceso en términos de relaciones, la metarrelación y la gobernanza relacional.

8. Proceso definido por relaciones interactivas en movimiento y las dinámicas por ellas generadas en la sociedad. Ontológicamente significativo, hace de las relaciones unidad de análisis primordial; mientras la Teoría occidental de las Relaciones Internacionales prioriza el análisis de los actores y la estructura del sistema internacional. Necesita por ello la Teoría de las Relaciones Internacionales de una teoría sistémica sobre las relaciones; y procede para ello recurrir al concepto de relacionalidad, que sostiene que el establecimiento relacional de redes en la Sociedad Internacional ayuda a los Estados-nación a formar sus identidades y genera poder internacional, al tiempo que se centra en las prácticas entre los actores internacionales y subraya la ontología independiente de los procesos y su incidencia en el desarrollo de las normas del sistema y las identidades de sus actores. Lo que implica un 
cambio de paradigma, de planteamiento, de perspectiva, de introducción del factor tiempo en el análisis.

9. Metarrelación o naturaleza de las relaciones y la lógica a ellas subyacente: frente a la hegeliana tesis-antítesis-síntesis y el pensamiento dicotómico de que una cosa no puede ser esa y la contraria; la de que el yin coexiste con el yang en un todo armónico y al tiempo lo genera, de que más que una tesis y una antítesis enfrentadas pueden existir y existen co-tesis simultáneas. La dialéctica china o Zhongyong (la "vía intermedia» o "vía mutuamente inclusiva»), establece la hipótesis de que las relaciones entre los dos polos (yin y yang) no son conflictivas, sino que pueden evolucionar juntas para formar una síntesis armoniosa, una nueva forma de vida que contiene elementos de los dos polos y que no se puede reducir a ningunos de los dos. Y tiende por ello a canalizar las relaciones por la vía de la cooperación.

10. Gobernanza relacional caracterizada por el énfasis en la negociación frente al control; la consideración de la gobernanza como un proceso de toma de acuerdos, destacando su naturaleza dinámica; la consideración de las relaciones, y no los actores, como el objeto de gobierno; y su fundamentación en la confianza.

11. Desde una perspectiva occidental, la propuesta de Qin Yagin no puede sino suscitar percepciones encontradas. Pues, por un lado, no puede sino compartirse el diagnóstico de que para articular la gobernanza global debe el Sistema Internacional fijarse en las relaciones y su gobierno; además de la estática y la estabilidad coyuntural, debe contemplar la dinámica y la evolución. Pero, por otro, para una Unión Europea y un Occidente que afrontan una perspectiva de disminución progresiva de su peso relativo en el sistema internacional en las próximas décadas, no puede dejar de recordarse aquel viejo adagio jurídico de que para el débil el Derecho es la fuerza, de que en ese mundo en que su poder no podrá ya imponerse la mejor garantía de pervivencia de sus valores y modelos de sociedad radica en la transformación del sistema internacional en un sistema de Derecho. En cualquier caso, nos muestra evolución reciente de la gobernanza global y la arquitectura diplomática — de APEC o ASEM al G20 — la plasmación e incidencia de las ideas asiáticas en los nuevos foros regionales y globales que canalizan las relaciones regionales e interregionales y la gobernanza global.

12. Recurre Yan Xuetong en su intento de reformulación de la Teoría de las Relaciones Internacionales al estudio del pensamiento político de los filósofos chinos anteriores a la unificación Qin y al de Las estratagemas de los reinos combatientes; y nos ofrece en Ancient Chinese Thought, Modern Chinese Power un itinerario analítico del que se desprenden conceptos relevantes para la Teoría de las Relaciones Internacionales, a partir de los que acometer su reconsideración, y lecciones aprendidas para el ascenso de China. Conceptos como el del Tianxia como el quién del Sistema Internacional, lo que hace de este un intento de regulación política del conjunto de la humanidad, necesitado de jerarquía y autoridad moral para la construcción de un mundo 
armonioso. $\mathrm{O}$ como el de poder y autoridad internacional, en el que, según el énfasis dado a la influencia o autoridad moral, distingue entre la autoridad compasiva o humanitaria, la hegemonía basada en el poder material y la tiranía, basada en el recurso a la fuerza militar y las estratagemas. Formula en este sentido su teoría del poder nacional total, que, a diferencia de la distinción aditiva entre poder duro y blando de Joseph Nye, destaca el carácter multiplicativo y determinante del poder político. Así, mientras Nye establece la distinción entre poder duro (PD) - que comprendería el poder militar (PM) y el poder económico (PE) - y poder blando - que comprendería el poder político (PP) y el poder cultural (PC) - , de modo que el poder total de una potencia sería no solo el poder duro sino también el blando, el resultado de la suma de ambos - Poder Nacional Total PNT $=\mathrm{PD}+\mathrm{PB}=\mathrm{M}+\mathrm{E}+\mathrm{P}+\mathrm{C}-$, sostiene Yan Xuetong que no es tal la fórmula que determina el poder total de una potencia, sino PNT $=(\mathrm{M}+\mathrm{E}+\mathrm{C}) \mathrm{x}$ P. Poder político a su vez determinado por la capacidad de atraer a los mejores a su servicio, lo que a su vez requiere la apertura. Autoridad compasiva o humana emanada en el mundo de hoy de la democracia como ideal compartido de la humanidad. Conceptos o teorías, también, sobre el conflicto inherente a la naturaleza humana, canalizable en sociedad a través del Derecho y las jerarquías que a su vez conllevan responsabilidades. O sobre los cambios en la estructura de poder en el sistema internacional y el ascenso de los poderes hegemónicos, respecto al que sostiene que no existe una estrategia definida y universal para alcanzar la hegemonía, sino que resulta la creatividad un elemento esencial al efecto, así como la capacidad de transformarse internamente, de producir ideas e innovar. Requiere también alcanzar el liderazgo mundial desarrollar las tres bases del poder, y un mínimo de poder o base material. Afronta en su ascenso toda potencia hegemónica el reto de proponer nuevas normas, de afirmarse como nuevo líder, y obtener aceptación, y resultan para ello claves las alianzas.

13. Formula a partir de ahí propuestas para la reconsideración de la Teoría de las Relaciones Internacionales, respecto a la investigación sobre el poder de las potencias; el Sistema Internacional; y la Teoría de la «Gran Estrategia» ("Grand Strategy», o estrategia para el ascenso al liderazgo global). Y considera que constituye el ascenso de China fundamentalmente una cuestión de gobernanza, interna e internacional. Interna, para construir una sociedad próspera y civilizada, considerando que debe superar la consigna de Deng Xiaoping de concentrarse en el crecimiento económico y mantener un perfil bajo en la arena internacional, y afirmando que ese impacto moral exterior requiere de la transformación interior, hacer del propio modelo de sociedad chino plataforma y ejemplo desde el que promoverlo. De la lectura de Mencio deduce que afronta China dos opciones fundamentales en su ascenso hacia el liderazgo global: convertirse en un Estado hegemónico que sustituya en el liderazgo a los que le han precedido, y que como los que le han precedido pierda su liderazgo un día, con el riesgo de que se cumpla en uno u otro proceso de cambio la maldición de Tucídides; o que su ascenso suponga un caso único en la Historia de ascenso o transformación al tiempo hacia la autoridad compasiva o humanitaria, rompiendo así los ciclos de la Historia y 
su repetición, y haciendo posible la transformación del propio Sistema Internacional hacia un punto de equilibrio superior. Considera en esa perspectiva que le falta a China en su política exterior un ideal moral universal, y que más bien es percibido internacionalmente como un Estado sediento de poder, percibido por algunos su ascenso como una amenaza a la estabilidad del Sistema Internacional. Y que para alcanzarlo y proyectarlo hacia fuera debe en primer lugar convertirse en sí misma en un modelo político y socioeconómico con vis atractiva hacia el exterior. Que el proceso de desarrollo y evolución de China no pasa solo por el aumento de su poder, sino también por la proyección de sus ideas y su modelo. Necesita China fortalecer y ampliar su liderazgo, y para ello fortalecer y desarrollar su poder en todos los ámbitos, atraer talento no solo en el económico, sino en todos, incluido el político; y, para ello, abrirse al mundo. Necesita superar las inercias que se derivan de los principios que han orientado su política y acción exterior, como las que se derivan de su participación en el Movimiento de los No Alineados, y optar por la creatividad, construir y desarrollar alianzas y conseguir apoyo internacional. Asumir que el Estado de Derecho, la democracia y la celebración de elecciones constituyen hoy norma universal de legitimidad. Promover un Orden Internacional basado en el equilibrio entre responsabilidades y derechos, que aplique el doble estándar inverso y asuma que «Todo bajo el cielo» es uno, puede resultar determinante en la evolución de China hacia la autoridad compasiva.

14. Más allá y junto al debate que se desarrolla en el mundo académico y de pensamiento chino sobre la Teoría de las Relaciones Internacionales y la configuración y transformación del sistema internacional, el que se da sobre la política exterior de China en la actual coyuntura y ante su perspectiva de ascenso global. Un debate que es objeto de análisis por Zhu Liqun en su trabajo China's Foreign Policy Debates, en el que nos ofrece para ello un esquema de análisis basado en los conceptos de $s h i$, identidad y estrategia, reflejando el estado de debate y los posicionamientos en torno a ellos. Shi: configuración de poder y estado y tendencia de evolución del mundo, que sería hoy la paz, el desarrollo y la cooperación, destacando el cambio de percepción china respecto al sistema internacional, de la oposición y el aislamiento al compromiso y la participación constructiva. Identidad internacional de China, determinada por su progresiva integración en este, en la sociedad y la economía internacional a partir de sus políticas de reforma y apertura, participando en el statu quo y asumiendo su responsabilidad y participación en su funcionamiento. Estrategia internacional de China, que afronta la disyuntiva entre concentrarse en el desarrollo y el incremento del bienestar de la población, o construir poder internacional y afirmarse como potencia.

15. Debate sobre la política exterior de China ante su ascenso global que presupone, por otro lado y a su vez, el debate sobre la identidad global de China, que al tiempo que constituye expresión de este lo relaciona con el debate sobre el Sistema Internacional y la Teoría de las Relaciones Internacionales. Debate que responde en definitiva a la concepción que pueda tener China de 
sí misma y de su papel en el mundo ante su ascenso global, respecto a lo que se dan diferentes posiciones o visiones entre los académicos, especialistas de think tanks y policy makers, no necesariamente excluyentes entre ellas, en algunos casos incluso simultánea y compatiblemente defendidas por algunos autores. Posiciones o visiones entre las que David Shambaugh, Director del China Policy Program de la George Washington University, distingue las de los nativistas, los realistas, los partidarios de fortalecer la relación con las grandes potencias, los partidarios de fortalecer la relación y proyección regional en Asia, los de promover la alianza global del Sur, los del multilateralismo selectivo y los globalistas; estableciendo un continuum entre ellas que definiría por ese posicionamiento relativo el espectro de las visiones o posiciones sobre la identidad global de China. Sostiene Shambaugh que la evolución reciente de la sociedad y la opinión pública china favorece el fortalecimiento de las visiones nativista y realista en el marco de un resurgir nacionalista, lo que condiciona la toma de posición de los decisores políticos; y se pregunta por las consecuencias del desarrollo de cada una de las escuelas o corrientes y la posible interacción desde Estados Unidos con ellas. Se pregunta, también, si el predominio de la visión o enfoque realista en China debería ser respondido por la priorización a su vez de este desde Estados Unidos, frente a lo que advierte del riesgo de retroalimentación negativa entre ambas visiones y sostiene el interés de promover una estrategia más sofisticada y compleja.

16. Debate sobre el Sistema Internacional y la Teoría de las Relaciones Internacionales, sobre la identidad global de China o sobre su política exterior a su vez reflejo y expresión del proceso de reflexión acometido en China sobre su propio ascenso global y sus implicaciones, posibilidades y responsabilidades, acometido con una profundidad y conciencia, con esa perspectiva y sentido histórico que otorga una Historia continuada de varios milenios, que constituye en términos comparativos una especificidad del ascenso global de China. Debate que se plantea cómo promover el «ascenso pacífico», por utilizar la denominación con que a partir de mediados de la pasada década vino a denominarse la conceptualización del ascenso global de China en el discurso oficial, combinada en este con la de un «mundo armonioso», frente a otras visiones triunfalistas defendidas por algunas voces y autores. Debate cuya comprensión nos lleva, por un lado, a la reflexión sobre el poder y su legitimidad; y, por otro, a la consideración de la cultura estratégica china, inscrita en una perspectiva histórica que carece de precedentes en el ascenso global de ninguna otra potencia en la Historia - que permite contemplar la emergencia actual como reemergencia y vuelta a la centralidad habitual-y de la que resulta ilustrativa la comparación entre las ideas subyacentes a la conducción de la guerra de Clausevitz y de Sun Tzu o al juego del ajedrez y del wei qi; entre ganar la guerra ganando batallas y ganarla sin llegar a tener necesidad de estas, entre la ocupación de la centralidad del tablero con el movimiento decisivo y la larga campaña de rodeo estratégico ocupando el vacío.

17. Tiene este debate exterior o sobre el exterior en el mundo académico y del pensamiento chino una doble dimensión más allá de su ámbito internacio- 
nal o exterior; pues si por un lado tiene una dimensión o reflejo interior, es por otro reflejo en el exterior de un debate global. Potencialidad transformadora interior, en el doble sentido de que un sistema internacional diferente puede justificar un sistema nacional diferente, y de la participación en la conformación de la universalidad global y la incidencia de esta en la universalidad de la propia evolución interior. Conciencia de que el sueño chino tiene que ser visto y vivido por los chinos y por el mundo como un sueño hecho realidad, un sueño que vale la pena soñar y vivir. Mas, también y al tiempo, reflejo en el exterior de una tendencia global: el recurso al neo-confucianismo como discurso legitimador y explicativo por parte de los detentadores del poder.

18. Propuestas, ideas que nos muestran que el tiempo interesante del ascenso global de China que vivimos es al tiempo el tiempo de las ideas chinas. Y de las ideas asiáticas. $\mathrm{O}$ del paso a estas desde los valores asiáticos que proclamara Lee Kwuan Yew frente al fin de la Historia de Fukuyama. Ideas a las que nos hemos referido en el ámbito de la Teoría de las Relaciones Internacionales, pero que podemos encontrar igualmente en la Economía y otras disciplinas del conocimiento humano.

19. Ideas, propuestas, reflexión desde China sobre la Teoría de las Relaciones Internacionales que cabe inscribir y que lleva a otras reflexiones, a otros debates. Sobre la política exterior y la identidad internacional de China; sobre su ascenso global y su cultura estratégica; sobre la dimensión interior del debate exterior, y sobre la legitimidad y el poder. Nos lleva, también, a las ideas asiáticas para la gobernanza global, como las formuladas desde Singapur por Kishore Mahbubani. Y a su transformación en realidad para su proyección internacional, como nos muestra el caso de Singapur. Debates y reflexiones sobre los que acometo, al igual que sobre el desarrollo de lo en estas líneas expuesto, un itinerario analítico en mi libro Ideas chinas. El ascenso global de China y la Teoría de las Relaciones Internacionales, y a su lectura al lector interesado remito.

20. ¿Qué ideas frente a las ideas chinas, qué reacciones, qué reflexiones, qué retos? Quisiera destacar, entre ellos, los que nos plantea desde España hacia y con China, hacia y con la Unión Europea y hacia nosotros mismos.

21. Hacia y con China, desde la conciencia de que nuestra relación con China no solo es esencial para nuestra economía e inserción económica internacional, sino para la conformación del mundo en que vivimos y del Sistema Internacional y su evolución; de que nuestra capacidad de propuesta, de pensamiento, de interacción e intercambio con China en el ámbito del pensamiento constituye un reto y un activo para nuestra acción exterior y nuestro posicionamiento internacional.

22. Hacia y con la Unión Europea, pues no puede España ir hacia China o plantearse las relaciones con China sino a través de la Unión Europea, como Unión Europea. Frente a China, en China se construye Europa. Constituye uno de los retos fundamentales de Europa en los próximas décadas pivotar hacia Asia, contar en ella, constituirse en actor significativo en su 
poder e inserción internacional. Lo que requiere pensar globalmente nuestra relación con China, y pensarla en relación al pensamiento, tener en cuenta el pensamiento chino sobre las Relaciones Internacionales. Lo que nos plantea a los europeos el reto de conocerlo, definir nuestro propio pensamiento, interactuar con él, buscar síntesis e ideas comunes para definir en común el futuro común y hacer posible la gobernanza global. Europa se construye, también, pensando frente a China y pensando con China.

23. Hacia nosotros mismos, especialmente y sobre todo. Pues la experiencia china de recurrir a su propia tradición cultural, a su Historia y a su Filosofía política, para intentar aplicar sus conceptos y lecciones a la comprensión del mundo de hoy y la conceptualización del sistema internacional, nos plantea en el espejo el interés de abordar la reflexión sobre estos desde nuestra propia experiencia y tradición. De recordar que hubo un momento en que España fue potencia hegemónica, en que descubrió un mundo nuevo y tuvo que pensar —o desde España se pensó- de nuevo el mundo. Y que ese pensamiento influyó decisivamente entonces en la conformación de la Teoría de las Relaciones Internacionales y en la conformación de los conceptos sustentadores del Sistema Internacional, que contemporáneamente nos llegan de fuera.

24. Decisiva fue, por poner tan solo un ejemplo, la controversia de Valladolid, la afirmación de la humanidad de los habitantes del Nuevo Mundo, y con ella de la universalidad de la condición humana y los derechos que de ella se derivan. España constituye, en su proyección y expansión global, un caso pionero y extraordinario en la Historia de reflexión moral sobre las implicaciones de sus descubrimientos, las condiciones y límites de la expansión de su poder y su ejercicio, las bases teóricas de la legitimidad del mismo. Una reflexión sobre las implicaciones globales e históricas de su ascenso que, salvando todas las distancias, observamos también ahora en China.

25. Decisivas también las aportaciones de Suárez y Vitoria, y en general de la Escuela de Salamanca, a la conformación del Derecho internacional, presentes sus ideas en los orígenes y fundamentos de lo que es hoy el Sistema Internacional. Ideas, por cierto, paradójicamente con mayores posibilidades de encuentro con las ideas chinas; pues responden a una Filosofía política del todo, a una lógica del bien común del todo por encima de las partes, anterior y superior a la fragmentación del poder y el equilibrio y contrapeso de poderes que orienta la estructuración del sistema internacional de Westfalia. Unas ideas, una filosofía, en ese sentido, que podrían dialogar o encontrarse con las que se derivan de la Tianxia...

26. Tendemos a veces o a menudo a olvidar nuestro legado, lo que fuimos, y no podemos sin tenerlo presente ser del todo lo que somos, lo que podemos ser...

27. Nos hablaban los clásicos del Gran Teatro del Mundo. Nos invita Gracián en El Criticón, de la mano de Critilo y Andrenio, a visitarlo en sus escenarios, escenas y episodios, como de un modo u otro han intentado e 
intentan describirlo tantos escritores. Si estos intentan describirlo en el papel, todos intentamos escribir con la vida en el mundo y en la vida. Escribir esa obra colectiva que llamamos Historia y queremos nuestra. Toda vida en sociedad interpreta una obra colectiva; y de algún modo todo debate político es un debate sobre los papeles y el argumento de la obra. Nos decía María Zambrano que el hombre es el único ser que no solo padece la Historia, sino también la hace; y en ese hacer, en ese querer hacerla, radica en buena medida su esencia y se cumple su ser.

28. ¿Cuál es la obra? ¿Cuál el escenario, el argumento, quiénes los protagonistas? Preguntas que todos nos hacemos. Todos somos actores y al tiempo autores, objeto y sujeto de acción colectiva. Local, estatal, internacional: depende del escenario en que nos situemos, de cómo apretemos el zoom. Si lo apretamos y encuadramos en gran angular el tiempo y el espacio, y contemplamos el Gran Teatro del Mundo, y vislumbramos hacia el futuro, desconocemos los argumentos y los escenarios de la obra; mas sabemos que esta cuenta en cualquier caso necesariamente con un actor protagónico y coescritor determinante. Y sabemos que se llama China.

29. Toda relación supone una metarrelación. Toda obra una metaobra. La Teoría de las Relaciones Internacionales es, en ese sentido, una teoría o construcción conceptual sobre el relato del relato, sobre el escenario, los papeles, los actores que los interpretan, las dinámicas en que se desarrollan sus acciones, los temas de sus conversaciones. Necesitamos un metarrelato compartido para un mundo compartido, construir entre todos la Teoría de las Relaciones Internacionales de todos. Necesitamos del diálogo entre la Tianxia y la polis y las ideas y tradiciones intelectuales que de ellas se desprenden. Dar, en definitiva, la bienvenida a las ideas chinas y afrontar el reto de con ellas desde las nuestras dialogar, construir universales compartidos y abiertos, escribir entre todos la obra de todos para la navegabilidad y navegación de la nave espacial Tierra, para que nuestro viaje sea el de esta destino futuro.

Palabras clave: China, Teoría de las Relaciones Internacionales, ideas chinas, pensamiento político chino, cultura estratégica china, ascenso global de China.

Keywords: China, Theory of International Relations, Chinese Ideas, Chinese Political Thought, Chinese Strategic Culture, China's Global Rise. 